\title{
An Investigation into the Mediating Influence of Customer Expertise on the Antecedents and Consequences of Affect within Professional Service Markets
}

This study examines the role of Affect evoked on satisfaction judgments among consumers of differing expertise within a credence service context. Whilst there is increasing evidence to suggest an empirical link between Affect evoked and satisfaction within such contexts, previous research has largely ignored the role of consumer expertise as a mediating influence. Using a scenario based approach, the objective of the study was to test for multi-group invariance among competing structural models based on the ability of the respondents to form expectation and performance assessments about the service they are receiving. The results indicate that it is important to examine different levels of consumer expertise in detail to better understand how certain characteristics such as experience and qualifications influence the priority and functionality attached to service attributes when making satisfaction judgments within credence services. This may in turn have broader implications for our contextual understanding of services

\author{
Tony Garry \\ De Montfort University
}

Paper Submitted to the Journal of Marketing Management 


\section{Introduction}

Research demonstrating an empirical link between Affect evoked and satisfaction in tangible product based contexts is well documented (e.g. Phillips and Baumgartner, 2002). Within credence service contexts however, the role of Affect becomes more ambiguous. More specifically, there is evidence to suggest that consumers will, in part, rely on Affect evoked as a result of interaction with the service provider (Alford and Sherrell, 1996). However, research has generally assumed consumer homogeneity (e.g. Smith and Bolton, 2002) and neglected the issue of how 'consumer expertise' may moderate Affect evoked and its role in determining satisfaction.

Augmenting earlier findings using regression analysis (Garry, 2007), this paper reports on a study which uses structural equation modeling (SEM) to examine the role and functionality of Affect on the formulation of satisfaction judgments within credence service encounters and to examine the mediating influence of consumer expertise. The paper is structured as follows. First, there is a brief synopsis of the recent literature on emotion and consumption satisfaction. Subsequently, two competing path models and research hypotheses are developed consistent with the research aims. The research design is then described and the results discussed. The paper concludes with implications and recommendations for future research.

\section{Literature Review}

Historically, Affect and more specifically, emotion was largely ignored within the marketing literature until relatively recently (Oliver, 1997). However, more recent literature has reflected an increased interest in Affect and its role within a range of marketing contexts. Examples of these include: the role of Affect in determining customer satisfaction development (Homburg et al., 2006); emotional contagion within service interactions (Hennig-Thurau et al., 2006); Affect infusion and wordof-mouth recommendations (Söderlund and Rosengren, 2007); customers' affective response to touch and its influence on persuasion (Peck and Wiggins, 2006) and crucially when considering the focus of this research; the link between satisfaction and emotions (White and $\mathrm{Yu}, 2005$ ).

When considering the role of Affect evoked on consumption satisfaction judgments, it is imperative to review the literature involving both so that the relationship between them may be fully comprehended .Early research in this area (Westbrook, 1987) has demonstrated that positive and negative Affect are independent dimensions related directly to product (dis)satisfaction judgments and that overall satisfaction is determined by a joint operation of product influences and Affect (Mano and Oliver, 1993). Subsequent findings also suggested that Affect may partially mediate product attribution influences on overall satisfaction (e.g. Oliver, 1993; Adaval, 2001).

However, the research findings reviewed so far have primarily been in tangible, product based contexts. From a services perspective, some inadequacies may be identified (Bickart and Schwarz, 2001). Firstly, where there is a high degree of interaction between service provider and consumer, the service provider may become the focal point of the service encounter (e.g. Schoefer and Ennew, 2005) and yet there is no provision for consumer reactions to the service provider (Alford and Sherrell, 1996). Secondly, it is assumed that the consumer has the ability to form expectation and performance assessments about the attributes of the core or technical product 
(Grönroos, 1984). However, this may not always be the case, particularly in a credence service context. In such circumstances, other dimensions such as the way the service is delivered or 'the functional product' (Grönroos, 1984) and Affect evoked during delivery (Barnes and Howlett, 1998) may take on a higher degree of significance when determining satisfaction judgments (e.g. Crosby and Stevens, 1987). Indeed, research by Alford and Sherrell (1996) suggests that consumers may use their affective reaction to the service provider when deriving satisfaction judgments.

However, previous research in this field has assumed that consumers are homogenous (e.g. Smith and Bolton, 2002) when there is increasing evidence to suggest consumer heterogeneity (e.g. Hanlon, 1997). This implies credence services may be consumed by individuals who, in varying degrees, possess the ability to form expectation and performance assessments about the service they are consuming and have pertinent technical qualifications, skills, knowledge and experience that enable them to do so. Consequently, the purpose of this research is to explore the role and functionality of Affect on the formulation of satisfaction judgments within credence service encounters and to examine the mediating influence of consumer expertise on this.

\section{Research Hypotheses and Model Specifications}

Whilst previous analysis of data collected for this research using regression techniques (Garry, 2007) revealed there may be differences in the way consumers of differing expertise form expectation and performance assessments, some of the results were ambiguous. Given the complex nature of the interrelations that appear to exist between the variables, a further analysis of the data using structural equation modeling (SEM) was considered appropriate for two reasons. Firstly, it allows for a simultaneous testing of antecedent and consequent structural relationships (McDougall and Levesque, 2000) thus providing a 'holistic' overview of these interrelations and therefore building on the previous findings of the multiple regression analysis (Baumgartner and Homburg, 1996). Secondly, it allows for the 'pinpointing' (Byrne, 2001:p. 187) of differences between groups by allowing a systematic testing of each individual structural weight for invariance. Consistent with this and the research aims, the following four research hypotheses are proposed:

$\mathrm{H}_{1}$ : Where there is a higher degree of consumer expertise, there will be a higher reliance on evaluation of the technical component rather than the affective, interaction or responsiveness components when gauging overall satisfaction.

$\mathrm{H}_{2}$ : Where there is a lower level of consumer expertise, satisfaction with the technical component of the service will be a function of Affect evoked.

$\mathrm{H}_{3}$ : Where there is a higher level of consumer expertise, Affect evoked will partly be a function of satisfaction with the technical component.

$\mathrm{H}_{4}$ : Where there is a lower level of consumer expertise, Affect evoked will make a higher contribution to overall satisfaction judgments than for consumers with a higher level of expertise. 
To explore these hypotheses, a multi-group, multi-model structural equation modeling approach was adopted (Scott-Lennox and Lennox, 1995). Competing models are compared with two sets of respondents (one set with the pertinent expertise and one without) to allow different relationships between variables across the groups to be contrasted and compared. To this end, two competing path diagrams are specified. Previously conducted exploratory factor analysis of the data on the affective and cognitive components suggested that the cognitive component of the service encounter may not only comprise of a technical element, but also suggests that the functional element may comprise of two further dimensions (see Appendix 1). Firstly, an interaction component was identified consisting of the items 'empathy', 'courtesy', 'involvement', 'reassurance and confidence' and 'clear and understandable language'. Secondly a responsiveness component was identified comprising of the items 'promptness' and 'accessibility' (see Appendix 4).

Model 1 (see Fig. 1) therefore proposes the three constructs of technical, interaction and responsiveness satisfaction directly affect overall satisfaction. Consumers with an appropriate level of expertise are able to make performance assessments about the service they are receiving and this has a direct impact on their overall satisfaction judgments. This is represented by the direct paths between technical, interaction and responsiveness satisfaction and overall satisfaction in the path diagram. Technical, interaction and responsiveness satisfaction may also evoke Affect (Westbrook, 1987) which, in turn, affects overall satisfaction (Mano and Oliver, 1993).

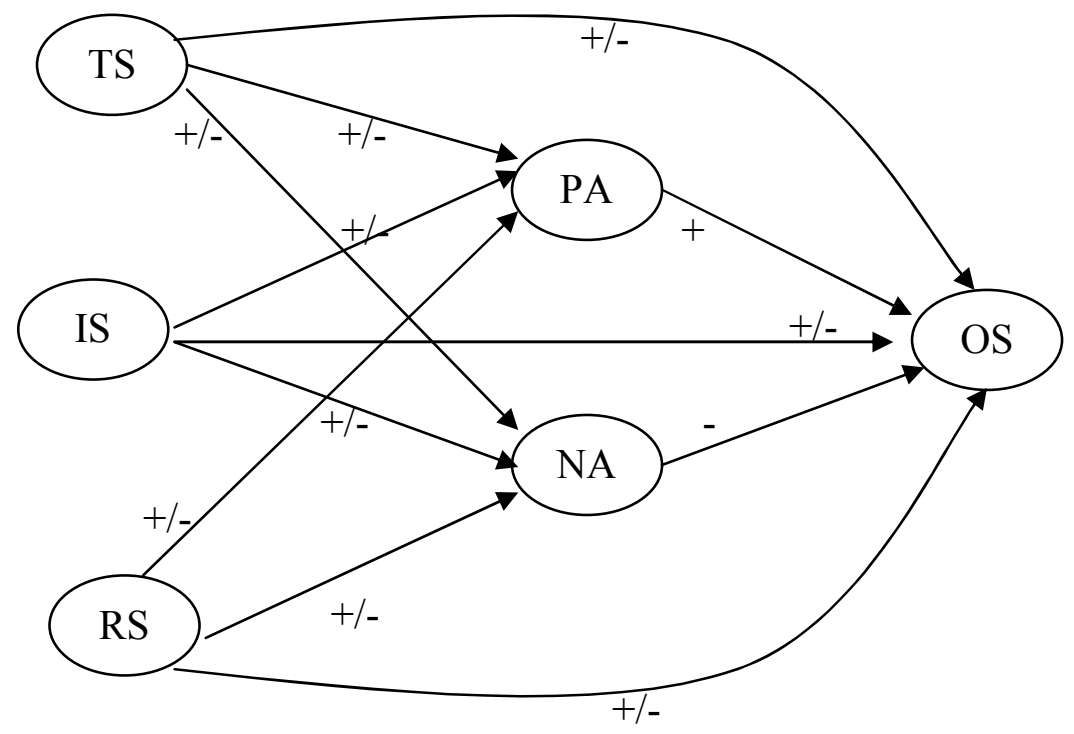

Fig. 1: Model 1: Conceptual Model of significant paths for consumers with a high level of expertise. TS=Technical Satisfaction; IS= Interaction Satisfaction; RS=Responsiveness Satisfaction; PA=Positive Affect; NA=Negative Affect; OS=Overall Satisfaction.

Model 2 (see Fig.2) proposes that interaction and responsiveness satisfaction evoke positive and negative Affect as well as contributing directly to overall satisfaction. However, because consumers with lower levels of expertise are unable to make performance assessments about the technical attributes of the service they receive, 
technical satisfaction is a function of Affect evoked and (dis)satisfaction with the interaction and responsiveness components of the service encounter (e.g. Alford and Sherrell, 1996). Technical satisfaction, positive Affect and negative Affect also contribute to overall satisfaction.

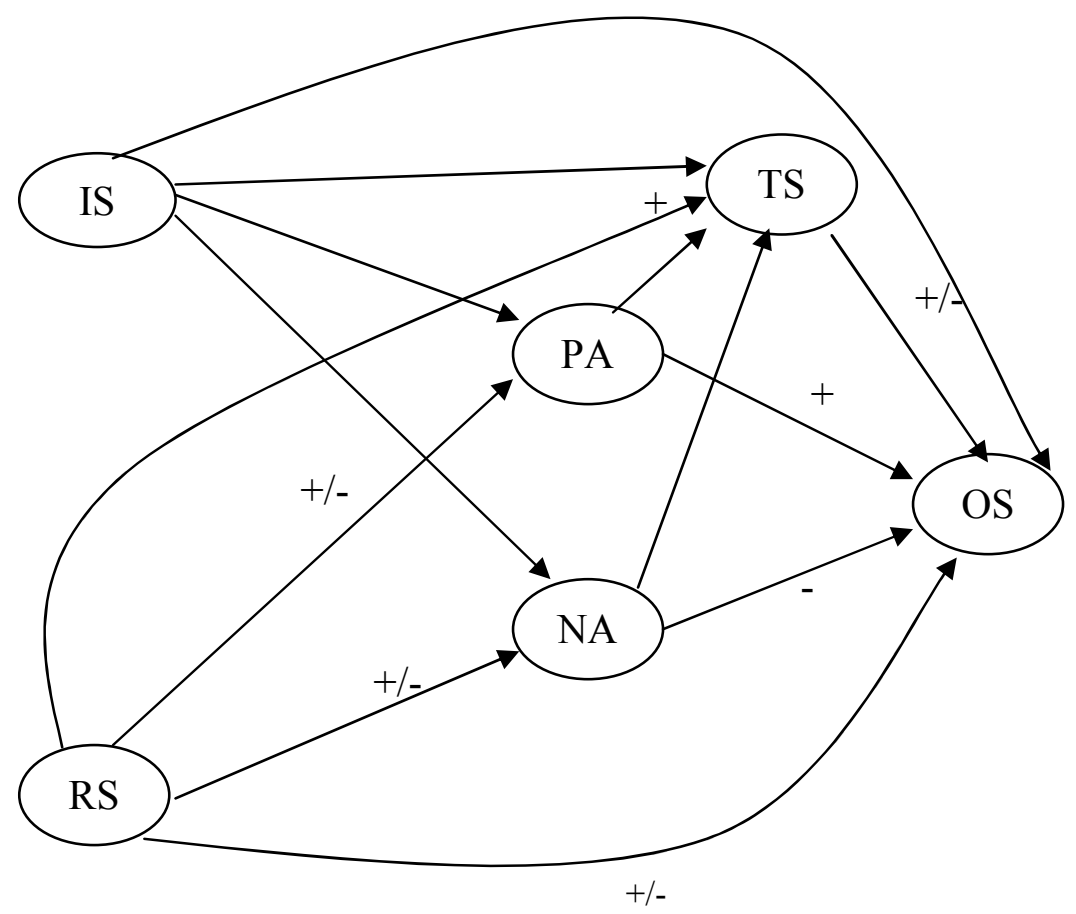

Fig. 2: Model 2: Conceptual Model of significant paths for consumers with a low level of expertise. TS=Technical Satisfaction; IS= Interaction Satisfaction; RS=Functional Satisfaction; PA=Positive Affect; NA=Negative Affect; OS=Overall Satisfaction.

\section{Methodology}

The hypotheses were investigated using data collected from a $2 \times 2 \times 2$ experimental design consisting of scenarios (Randall and Gibson, 1990). Experimentally generated scenario testing has been recognised and widely used as a valid data gathering technique within a number of contexts ranging from jury decision making (Landy and Aronson, 1969) to social status perception (Nosanchuk, 1972) and latterly, marketing (e.g. Schoefer and Ennew, 2005; Söderlund, 2006). The adoption of this approach may be justified for the current research as it facilitates the manipulation of the attributes of the service encounter (Söderlund, 2006) and crucially, it allows for the possibility of a clear differentiation between those consumers with the appropriate expertise and those without.

The scenarios used describe a service encounter between a client and a solicitor in a local law firm. The scenarios were manipulated to produce positive and negative outcomes in terms of the correctness of the legal advice given by the solicitor (technical: positive and negative), the process of the delivery of the advice (functional: positive and negative) and the nature of interaction between the solicitor and client (Affect: positive and negative) (see Appendix x). 
The convenience sample consisted of part-time students studying for a postgraduate qualification at a UK university. Fifty-four responses were from students studying for the Postgraduate Legal Practice Certificate and therefore judged to have a higher than average knowledge of the law. This set was labeled LPC (Legal Practice Certificate) respondents. Sixty-four responses were received from students studying for a postgraduate, business related qualification and therefore deemed to have an average knowledge of the law. This set was labeled NLPC (Non-legal Practice Certificate) respondents.

Student respondents were judged appropriate for this research as it allowed for a greater degree of control in terms of the identification and classification of respondents. Relevancy of scenarios (Mathison, 1998) was ensured by using mature post-graduate, part-time students primarily working in a business or legal context so that the details presented in the scenarios would be relevant and familiar. Particular care was taken with the construction of the technical element of the service encounter to ensure that the legal advice proffered by the solicitor in the scenario revolved around a case in law that the law students (studying for a Legal Practice Certificate or LPC) should recognise as being correct or incorrect. Subjects were randomly assigned to the scenarios and were asked to read the scenario and complete the attached questionnaire.

The questionnaire comprised five sections. The first section of the questionnaire was designed to ascertain the respondent's level of expertise in terms of their ability to form performance assessments about the service and to evaluate their perceived realism of the scenarios. The second section of the questionnaire contained a number of scale items used to measure satisfaction relating to the cognitive element of the service. These were based on Hart and Hogg's (1998) service evaluation criteria scale developed for legal services and incorporated an assessment of the actual legal advice given and the legal calibre of lawyer providing the advice (i.e. the technical element) as well as the interaction with the client (i.e. the functional element) (see Appendix 2). The third section of the questionnaire contained a number of scale items related to the affective component of the service based on Richins (1997) Consumption Emotions Set (CES). The CES is now widely accepted and used within consumption marketing as an appropriate measure of emotions evoked during and as a result of consumption (e.g. Wood and Moreau, 2006; Söderlund and Rosegren, 2005; Bagozzi et al., 1999). Overall satisfaction was measured using a single item 5-point Likert scale (e.g. Cronin and Taylor, 1992; Odekerken-Schroder et al, 2000). The final section of the questionnaire consisted of questions designed to collect classification data. After extensively pre-testing the questionnaire and incorporating feedback provided as appropriate, the questionnaire was administered.

\section{Data Analysis}

The data was analysed in five separate but sequentially related steps with the first two steps incorporating analysis previously conducted on the data. Firstly, the data was subjected to a number of standard procedures to check for missing values and multivariate normality. Reliability and validity checks were also conducted. Secondly, an exploratory factor analysis was conducted to examine the empirical data structure. The primary aim of this was to assess if the appropriate items loaded onto their 
hypothesised factors. Thirdly, confirmatory factor analysis was conducted based on the results of the exploratory factor analysis. Fourthly, a multi-group, multi-model structural equation modeling approach was adopted (Scott-Lennox and Lennox, 1995). Initially, each model was tested against the two respondent data sets (see Fig. 3: Analysis 1 and Analysis 2) so to allow different relationships between variables across the groups to be analysed (Astor et al. 2006). In stage five, the 'competing models' were tested within each respondents' data set to ascertain which model best fitted the data. Initially, Model 1 and Model 2 were examined relative to the data set for the LPC respondents (see Fig 3.: Analysis 3) and subsequently Model 1 and Model 2 were examined relative to the data set for the NLC respondents ( see Fig. 3: Analysis 4).

LPC Respondents $\quad$ NLPC Respondents

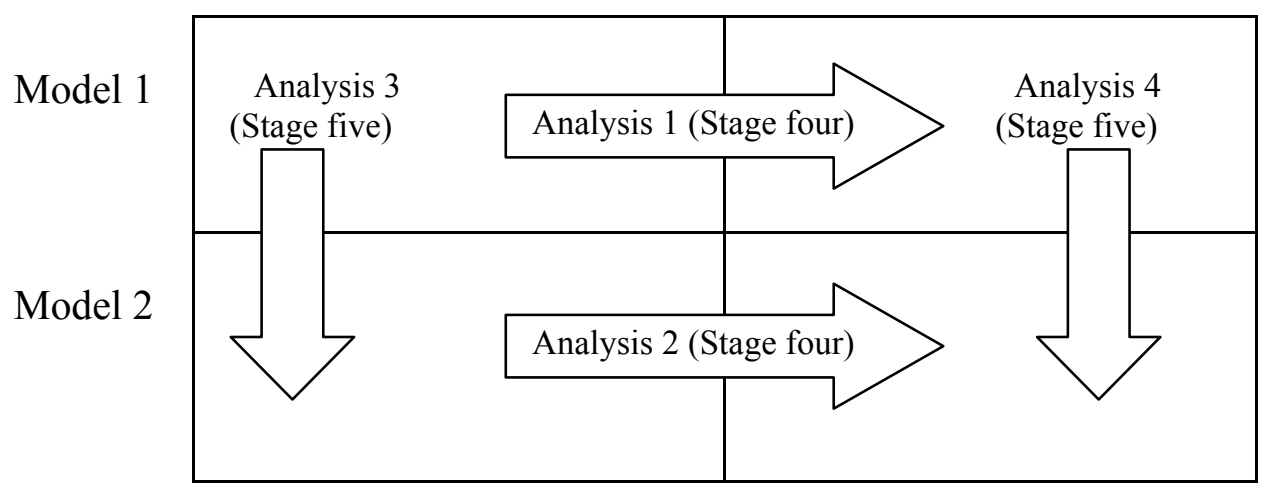

Fig 3: Multi-group and multi-model structural equation modelling approach adopted for the analysis

\section{Findings}

\section{Reliability and Validity}

Previously conducted checks suggested the respondents perceived the scenarios to be highly realistic. In response to the item "I believe that such an incident can happen in real life" (5= "Agree strongly" and 1= "Disagree strongly") a mean score of 4.14 was achieved (LPC $\bar{x}=4.15$ and NLPC $\bar{x}=4.13$ ). An independent paired sample t-test was not significant suggesting that there were no differences in the perceived realism of the scenarios between the groups.

A check conducted to ensure that respondents were correctly classified according to their ability to form expectations and performance assessments about the attributes of the technical product. In response to the question "Was the legal advice given correct?" ('Yes,' 'No' and 'Don't Know'), a number of the LPC respondents (8) gave the incorrect answer or replied 'Don't Know' (7). Analysis also revealed that a number of the NLPC responses (16) gave the correct answer to the same question. These responses were re-classified as appropriate.

Independent sample t-tests had also been conducted to ensure that the results of manipulations of the scenarios were in the anticipated direction. These results largely 
showed statistically significant differences in the expected direction between and within group means $(p<.05)$. These results also demonstrated that the NLPC group, in contrast to the LPC group were unable to make performance assessments about the technical element (i.e. the correctness of the legal advice) of the service encounter.

\section{Exploratory Factor Analysis}

The initial EFA previously conducted on the affective component (Garry, 2007) had resulted in a two-factor solution accounting for $54.7 \%$ of the variance with the results substantiating the existence of positive and negative affective dimensions to the service encounter (Westbrook, 1987; Oliver, 1993). The first factor was characterised by negative emotions (29.62\% of variance) and the second factor was characterised by positive emotions (29.14\% of variance) (see Appendix 3). The cognitive component of the service encounter was also subjected to a principal component factor analysis with a Varimax rotation). The loading of these items was different to expectations as it was anticipated that the variables would load across the two factors of the functional and technical product (Gronroos, 1984). However, as indicated previously, the analysis resulted in a three-factor solution accounting for $68.59 \%$ of the variance. The three factors were characterised by a technical element accounting for $22.48 \%$ of the variance, an interaction element accounting for $27.47 \%$ of the variance and a responsiveness element accounting for $20.16 \%$ of variance (see Appendix 1). The reliability of all the scales was established by utilising Cronbach's alpha. For the affective component, negative Affect and positive Affect had alpha scores of .94 and .95 respectively. For the cognitive component, the interaction element, the technical element and the responsiveness element had scores of $.85, .80$ and .74 respectively. These values are all above .7 so the scales can be considered reliable for this sample

\section{Confirmatory Factor Analysis}

The measurement model was derived from the results of the exploratory factor analysis and tested all five factors and 43 indicators. The results show that:

- the absolute values of the factor intercorrelations are significantly below one (see Appendix 5), providing discriminant validity of the constructs (Kumer et al ,1998)

- all the factor loadings of items on correspondent constructs are significant $(p<.001)$, demonstrating convergent validity for each of the measures (Kumar et al, 1998) (see Appendix 6)

\section{Testing for Invariance between Respondent Groups}

The structural models were based on a total aggregation approach where a single composite construct was formed by combining all the observed measures of that construct identified during the exploratory factor analysis (Bagozzi and Heatherton, 1994). Appropriate tests were conducted to identify if and how the structures between the latent variables were noninvariant between groups within each model (see Table 1). This was initially estimated by fully constraining the parameters of each model and comparing it with the relevant unconstrained model (Jøreskog, 1993). 


\begin{tabular}{|llccccc|}
\hline \multicolumn{1}{|c}{$\begin{array}{c}\text { Model } \\
\text { Description }\end{array}$} & $\begin{array}{c}\text { Comparative } \\
\text { Model }\end{array}$ & $\boldsymbol{x}^{\mathbf{2}}$ & $\boldsymbol{d f}$ & $\boldsymbol{\Delta} \boldsymbol{x}^{\mathbf{2}}$ & $\boldsymbol{\Delta} \boldsymbol{d f}$ & $\begin{array}{c}\text { Statistical } \\
\text { Significance }\end{array}$ \\
\hline $\begin{array}{l}\text { Model 1 } \\
\text { (Unconstrained) }\end{array}$ & Model 1 & .658 & 1 & & & .445 \\
$\begin{array}{l}\text { Model 1 } \\
\text { (Constrained) }\end{array}$ & (Unconstrained) & 52.47 & 28 & 51.89 & 27 & .003 \\
\hline $\begin{array}{l}\text { Model 2 } \\
\text { (Unconstrained) }\end{array}$ & $\begin{array}{l}\text { Model 2 } \\
\text { Model 2 } \\
\text { (Constrained) }\end{array}$ & 30.12 & 3 & & & .000 \\
\hline
\end{tabular}

Table 1: Results of global test of invariance between respondent groups for Model 1 and Model 2

Note: $\Delta x^{2}=$ Difference in $x^{2}$ values between models; $\Delta d f=$ difference in number of degrees of freedom between models

The results suggest that some equality constraints are not appropriate for both groups (Model 1: $\Delta x^{2}=51.89$ ( $\left.\Delta 27 \mathrm{df}\right) ; p<.05$; Model 2: $\Delta x^{2}=51.63$ ( $\Delta 27 \mathrm{df}$ ); $p<.05$ ). Subsequent testing was conducted to 'pinpoint the location' of the noninvariance by systematically testing each individual structural weight. (Byrne, 2001:p. 187). Where group invariance was identified, the parameters were cumulatively constrained equal while subsequent tests were conducted .

In Model 1, the source of the noninvariance related to the path Technical Satisfaction $\longrightarrow$ Positive Affect $\left(\Delta x^{2}=15.07(\Delta 1 \mathrm{df}) ; p<.05\right)$ and in Model 2, the source of noninvariance related to the path Positive Affect $\longrightarrow$ Technical Satisfaction $\left(\Delta x^{2}=10.725(\Delta \mathrm{dd}) ; p<.05\right)$.

\section{Testing for Model Fit}

Having identified the sources of noninvariance across groups for each model, the relevant parameters were unconstrained (Pousette and Hanse, 2002). Differences in model fit values were then used to estimate which model better fitted the relevant data pertaining to each group (see Appendix 7 and 8). The resultant structural models may be seen in Figs. 4,5 and 6. 


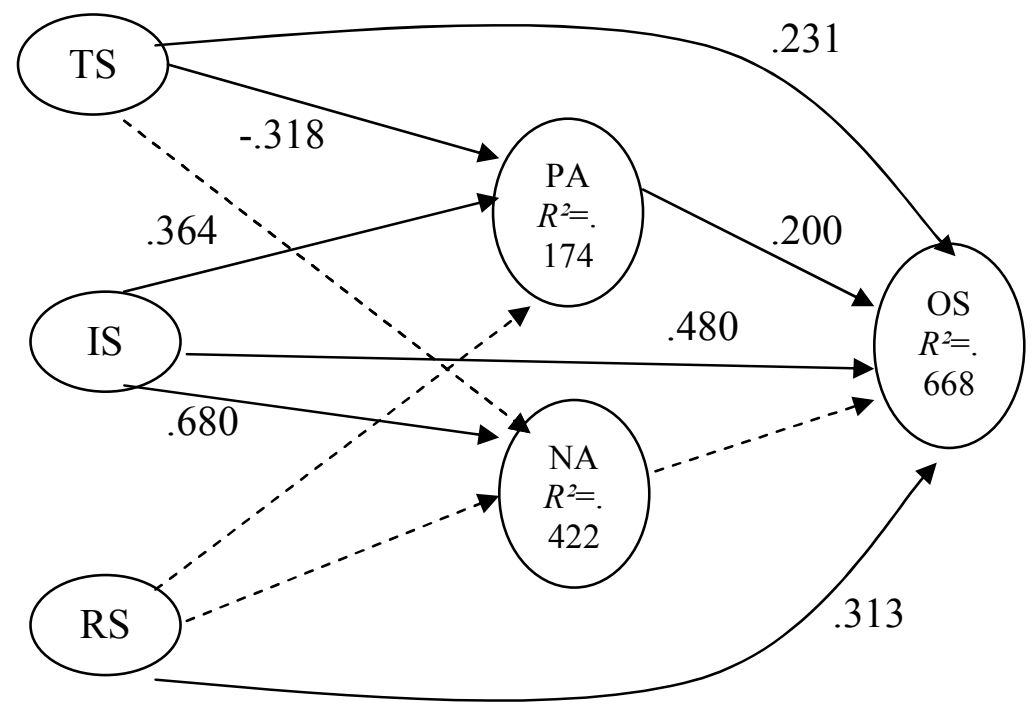

Fig. 4 : Model 1: Path Model of significant paths for LPC respondents $(\longrightarrow$ significant at $p<.05)$ . TS=Technical Satisfaction; IS=Interaction Satisfaction; RS= Responsiveness Satisfaction; PA=Positive Affect; NA=Negative Affect; OS=Overall Satisfaction.

As anticipated, for the LPC group (see Fig. 4), Model 1 was a considerable better fit than Model 2 with all measure within acceptable boundaries $\left(x^{2}=.084\right.$ ( $\left.1 \mathrm{df}\right) ; p=.772$, $\mathrm{GFI}=.999, \mathrm{AGFI}=.989, \mathrm{NFI}=.999$, RMSEA $=.000)$. The model explains $66.8 \%$ of the variance for overall satisfaction. Overall satisfaction was directly affected by the cognitive components of technical satisfaction $(\beta=.231, p<.05)$, interaction satisfaction, $(\beta=.480, p<.05)$, and responsiveness satisfaction $(\beta=.313, p<.05)$. Overall satisfaction was also affected by positive Affect $(\beta=.200, p<.05)$, which was in turn affected by interaction satisfaction $(\beta=.364, p<.05)$, and technical satisfaction $(\beta=-.318, p<.05)$. Negative Affect is affected by interaction satisfaction $(\beta=.680$, $p<.05)$ but does not directly affect overall satisfaction. The model explains $17.4 \%$ and $42.2 \%$ of the variance for positive and negative Affect respectively.

For the NLPC group, the results are more ambiguous insofar as the data fit for both models is within acceptable parameters with Model 1 having a slightly better fit than Model 2. (Model $1: x^{2}=.484$ ( 1 df) $; p>.001, \quad \mathrm{GFI}=.997$, AGFI=.945, NFI $=, 997$, RMSEA $=.000 ;$ Model $2: x^{2}=8.22$ (3df) $; p>.001$, GFI $=.960, \mathrm{AGFI}=.722, \mathrm{NFI}=952$, RMSEA $=.160$ ). 


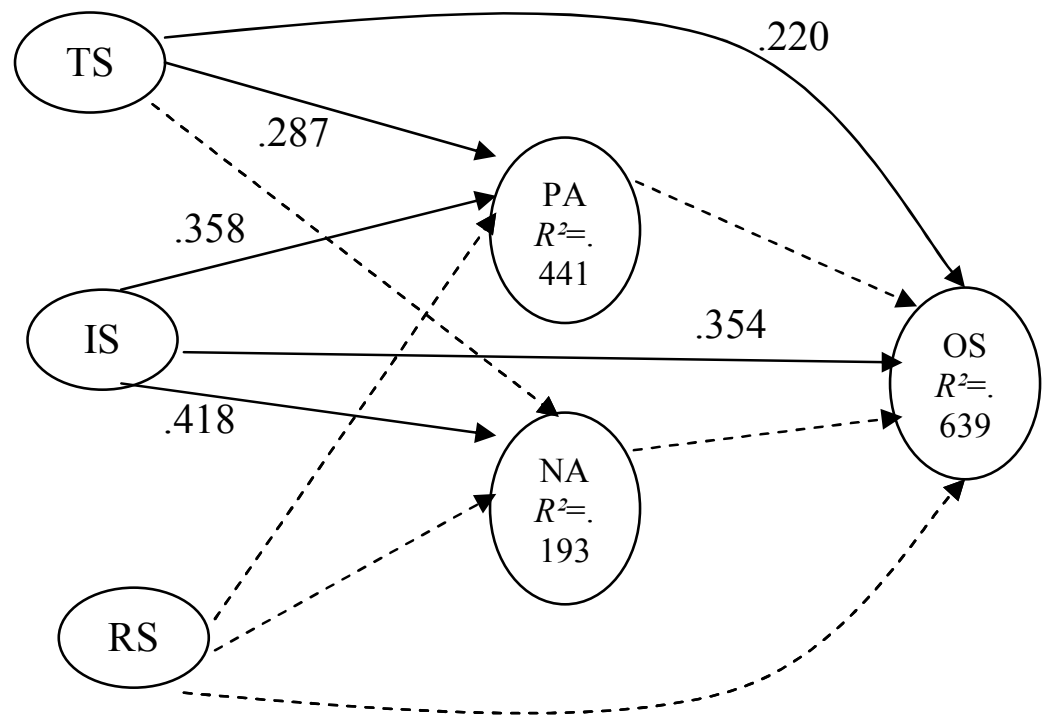

Fig. 5: Model 1: Path Model of significant paths for NLPC respondents $(\longrightarrow$ significant at $p<.05$ ) . TS=Technical Satisfaction; IS=Interaction Satisfaction; RS= Responsiveness Satisfaction; PA=Positive Affect; NA=Negative Affect; OS=Overall Satisfaction.

For Model 1 (see Fig. 5) the model explains $63.9 \%$ of the variance for overall satisfaction. Overall satisfaction is directly affected by technical satisfaction $(\beta=.220$, $p<.05)$, and interaction satisfaction $(\beta=.354, p<.05)$. In contrast with the LPC group, responsiveness satisfaction is not significant. Significantly, neither positive Affect nor negative Affect directly influence overall satisfaction. Positive Affect is affected by technical satisfaction $(\beta=.287, p<.05)$ and interaction satisfaction $(\beta=.358, p<.05)$ and negative Affect is affected by interaction satisfaction only $(\beta=.418, p<.05)$. The model explains $44.1 \%$ and $19.3 \%$ of the variance respectively for positive and negative Affect..

In Model 2 (see Fig.6), 62.5\% of the variance for overall satisfaction is explained. Overall satisfaction is directly affected by technical satisfaction $(\beta=.225, p<.05)$, and interaction satisfaction $(\beta=.361, p<.05)$. Once again, responsiveness satisfaction is not significant. Similar to Model 1, neither positive Affect nor negative Affect directly influence overall satisfaction. However, the model does explain $30.6 \%$ of the variance for technical satisfaction. Technical satisfaction is, in turn, affected by positive Affect $(\beta=.514, p<.05)$ which is, in turn, affected by interaction satisfaction $(\beta=.424, p<.05)$. 


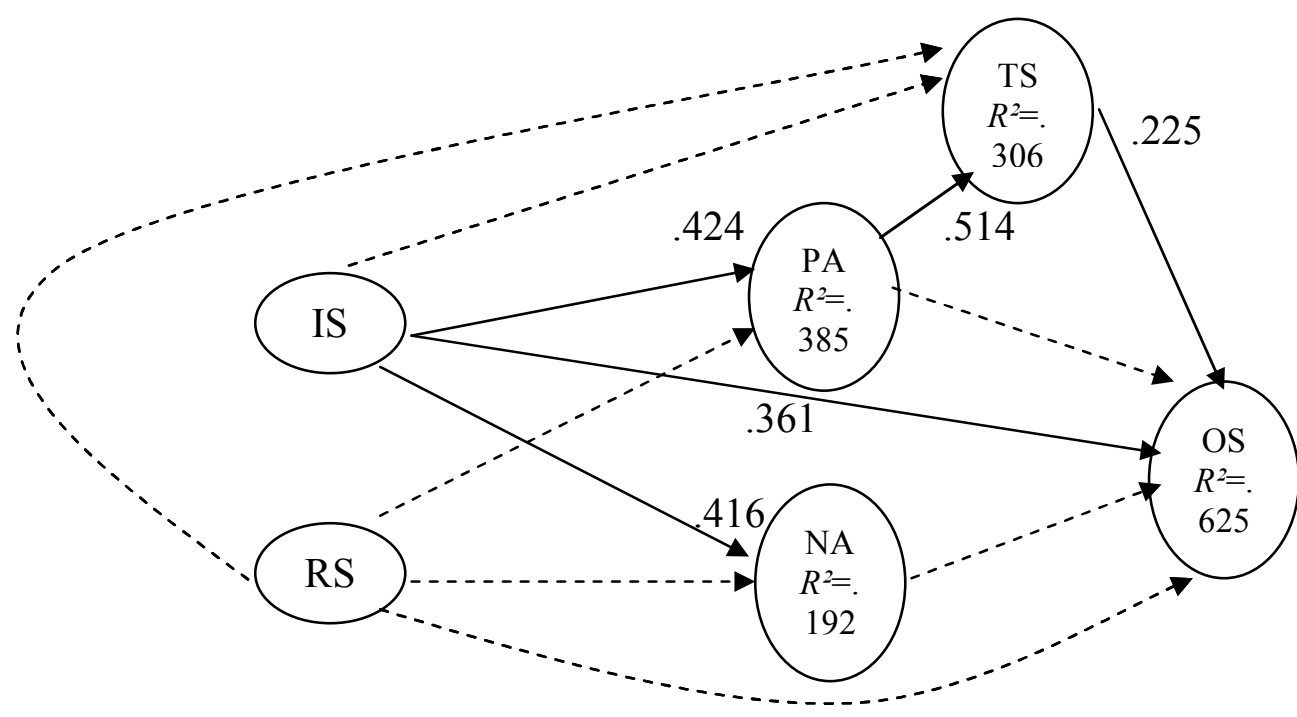

Fig. 6 : Model 2 : Path Model of significant paths for NLPC. respondents ( $\longrightarrow$ significant at $p<.05)$ TS=Technical Satisfaction; IS=Interaction Satisfaction; RS=Responsiveness Satisfaction; PA=Positive Affect; NA=Negative Affect; OS=Overall Satisfaction.

\section{Discussion}

$\mathrm{H}_{1}$ is rejected. Where there is a higher level of consumer expertise, satisfaction with the technical attributes of the service makes a slightly higher contribution to overall satisfaction judgments than positive Affect. However, it does not make a more important contribution than the interaction or responsiveness components of the functional product.

$\mathrm{H}_{2}$ is rejected. The data for the NLPC respondents appears to fit both competing models well. This perhaps explains some of the ambiguities identified when using more traditional regression techniques. With Model 1, the results are contrary to expectations insofar as the results of the manipulation tests conducted initially suggest that NLPC respondents are unable to make performance assessments about the technical attributes of the service encounter as they do not possess the necessary knowledge to do so. This suggests other moderating variables not included in the model may have influenced satisfaction judgments for this group. Many of the NLPC respondents work in full time managerial positions with some at a senior level. Whilst they may have no direct knowledge of the case in hand, their professional experiences may inform their satisfaction judgments. This 'intuitive logic and consistency with which the service process is performed' (Alford and Sherrell, 1996: p.73) may have a more significant impact than initially anticipated and future research should take this into consideration.

With model 2, the results appear to substantiate the findings of Alford and Sherrell (1996) insofar as where the consumer has difficulties in assessing performance, their affective reaction to the service provider during the service encounter may affect performance evaluations of the technical element. In such circumstances, satisfaction 
with technical attributes of the service may be interpreted as being a function of Affect evoked during service interaction.

$\mathrm{H}_{3}$ is partially substantiated insofar as, whilst negative Affect evoked through satisfaction with the technical component is not significant, there is an unexpected negative relationship between technical satisfaction and positive Affect. One possible explanation for this is that factors which detract from evaluation of the core or technical service for this group may be viewed as being superfluous and, in this instance, possibly detrimental to an unimpeded evaluation of the technical performance

$\mathrm{H}_{4}$ is rejected. Whilst positive and negative Affect is clearly evoked during interaction with the service provider for less expert consumers, neither makes any direct contribution to overall satisfaction thus contradicting earlier findings (e.g. Westbrook, 1986; Oliver, 1997). Alford and Sherrell (1996) discuss the existence of a dimension they subsequently label 'General Affect'. General Affect is defined as 'the existing affect stored with the service category, in the mind of the consumers' ( $\mathrm{p} .75)$. This is a broad level Affect that has been generated over time by past experiences with service provider categories (e.g. lawyers) and is not linked to any individual service provider. The results of Alford and Sherrell's (1996) research suggest that whilst general Affect does not directly affect overall satisfaction, it does significantly influence it indirectly through service interaction. The differentiation of general Affect and provider Affect and the role and functionality it plays in credence based services is perhaps a rich area for future research. One interesting finding to emerge for the LPC group was that whilst positive Affect evoked through interaction makes a statistically significant contribution towards overall satisfaction, negative Affect does not. One possible explanation for this is that many areas of law are implicitly confrontational. Respondents from a legal background may therefore anticipate that interaction with solicitors will contain some degree of contention and therefore negative Affect evoked does not detract from overall satisfaction. In contrast, when the interaction is non contentious, positive Affect is evoked

Taken overall, these results may have broader implications for our contextual understanding of services. Whilst there has been some debate surrounding what constitutes a 'professional service' within the marketing literature (e.g. Thakor and Kumar, 2000), consensus suggests that legal services generally falls within this category (e.g. File et al., 1994; Millman et al, 1991; Hilte et al, 1990; Congram, 1991; Bloom, 1984). Indeed, when reviewing the literature on the classification of professional services, Thakor and Kumar (2000) state that 'There seems to be a consensus among sociologists only about doctors, lawyers and clergymen' (p. 66). This then raises the issue of what criteria have been advanced to distinguish one category of service from another. Historically, the focus has been on the tripartite classification system called the 'search, experience and credence' (SEC) typology. Typically, the marketing literature has classified professional services generally and legal services in particular, as possessing credence characteristics (e.g. Bloom, 1984; Parasuraman et al 1985; Hill and Neely, 1988). However, the results of this research suggest this may be inappropriate and that the SEC classification typology may be overly simplistic within particular service contexts. 
Whilst the SEC classification typology has 'virtually gone unchallenged since its first advancement nearly a quarter of a century ago' (Mittal, 2004: p. 445), marketers have, over time, augmented it by drawing on the behavioural sciences literature whilst interpreting this element of micro economic theory. Thus, the assumption that consumers are reliable, rational and objective 'demanders of the product' has been adulterated insofar as consumers may be hypothesised as using personal inspection, product trial, word-of-mouth recommendations and marketing cues (e.g. Zeithaml, 1981).

Whilst the typology is useful as a generalised classification system for services, it does not appear to account for the variations in consumer expertise within a particular marketing context. There is s tendency to focus on the inherent attributes of the service as a means of generic service classification (e.g. Alford and Sherrell, 1998, Muhanna and Wolf, 2002) rather than considering the heterogeneous nature of consumers and their differing abilities they posses to make performance assessments about the service. Thus, according to the extant theory, credence attributes are not assessable even after purchase and consumers must rely 'essentially on trust and faith' ( Mittal ,2004: p. 450). This research demonstrates that this may not always be the case and that consumer expertise will be a determinant factor as to how service expectations are set and evaluations of service delivery are made.

Perhaps a more appropriate service distinction within this context is the 'accessibility' and 'assessability' (Mittal, 2004) of service attributes from a consumer perspective. Mittal (2004) defines service attribute accessibility as "a property of attributes as it resides in the product or service". In contrast, "assessibility uses the product attributes as a starting point and implicates the assessor's ability' (p.456). Thus, within this context while all the attributes of the service encounter may be experienced and thus accessible, its assessibility in terms of determining overall satisfaction judgments may be dependent on the expertise of the client.

Understanding how consumers perceive a particular service in terms of its attributes may help practitioners manage the marketing of that service to consumers of differing expertise. Thakor and Kumar (2000) highlight the importance that customer perceptions of the 'professionalism' of a service may have in terms of respect for the provider's expertise.

\section{Conclusion}

Research within professional service contexts has concentrated on examining the interpretation and transformation of consumer difficulties into some form of technical solution. However, understanding the business and commercial issues facing their clients may only be one consideration in determining levels of satisfaction. This research suggests emotional intelligence and sensitivity may also be pertinent and credence service providers should focus on these 'softer' attributes to a greater extent when considering interactions with their clients. Barsade (2002) highlights the importance of emotional contagion and how 'catching another person's emotions' ( $p$. 644) may affect the dynamics of interaction However, whilst this study augments these findings by demonstrating a link between Affect evoked through interaction and its direct impact on overall satisfaction judgments for some consumers, with others, the link is less direct. Never the less, credence service providers and their employees 
need to be aware and sensitive to the issue that the transfer of emotions from employees to clients through sincere and authentic emotional contagion and how this may, with some consumers, influence overall satisfaction levels. This may require additional training that teaches the processes of 'deep acting' such as perspectivetaking techniques (Hennig-Thurau et al.,2006).

\section{Limitations and Recommendations for Future Research}

Caution needs to be exercised when interpreting these results. Whilst scenario tests have a number advantages, as indicated by the results here, a mental simulation may fail to capture all of the complexities and subtleties of real-world service delivery and its assessment. The distinction between consumers with or without the pertinent expertise may perhaps be considered arbitrary. Previous research and the results of this analysis suggest this is over simplistic. Whilst a level of variance is explained in the models, there could be other factors external to the models that explain higher levels of variance. Variables that should be considered for inclusion in future models revolve around the dimension of intuitive logic, experience and a differentiation between provider and general Affect. For these reasons, further research is required into the relationship between consumer expertise, the assessments of the elements of the service encounter and their affect on overall satisfaction. Future studies that incorporate real consumers of differing expertise within differing credence contexts is recommended. From this, broader inferences and generalisations may be derived and sectorial and stakeholder norms established within differing credence contexts perhaps for benchmarking purposes.

\section{References}

Adaval, R., (2001), "Sometimes it Just Feels Right: The Differential Weighting of Affect-Consistent and Affect-Inconsistent Product Information", Journal of Consumer Research, Vol. 28 , June.

Alford, B. and Sherrell, D., (1996), "The Role of Affect in Consumer Satisfaction Judgments of Credence-Based Services", Journal of Business Research, Vol. 37, pp. 71-84.

Astor, A. Benbenishty, R. Vinokur, A. \& Zeira A. (2006), “Arab and Jewish Elementary School Students' Perceptions of Fear and School Violence: Understanding the Influence of School Context", British Journal of Educational Psychology, Vol. 76, pp. 91-118.

Bagozzi, R. P. Gopinath, M. \& Nyer, P. (1999), "The Role of Emotions in Marketing", Journal of the Academy of Marketing Science, Vol. 27, No. 2, pp. 184206.

Baggozzi, R.P and Heatherton, T.F., (1994), "A General Approach to Representing Multifaceted Personality Constructs: Application to State Self Esteem", Structural Equation Modeling, Vol.1, pp. 35-67. 
Barnes, J. and Howlett, D., (1998), "Predictors of Equity in Relationships between Financial Service Providers and Retail Customer", International Journal of Bank Marketing, Vol. 16, No. 1, pp15-23.

Barsade, S., (2002), “The Ripple Effect: Emotional Contagion and its Influence on Group Behaviour", Administrative Science Quarterly, No. 47, pp. 644-75

Baumgartner, H. \& Homburg, C. (1996), "Applications of Structural Equation Modeling in Marketing and Consumer Research: A Review", International Journal of Research in Marketing, Vol. 13, pp. 139-161.

Bickart, B., and Schwarz, N., (2001), "Service Experiences and Satisfaction Judgments: The Use of Affect and Beliefs in Judgment Formation", Journal of Consumer Psychology, Vol. 11, No. 1, pp.29-41.

Byrne, B., (2001), Structural Equation Modeling using Amos: Basic Concepts Applications and Programming, Lawrence Erlbaum Associates.

Cronin, J. and Taylor, S., (1992), "Measuring Service Quality: A Re-examination and Extension” Journal of Marketing Management, Vol. 56, July, pp. 55 - 68

Crosby, L.A. and Stephens, N., (1987), "Effects of Relationship Marketing on Relationship Satisfaction, Retention and Prices in the Life Insurance Industry”, Journal of Marketing Research, Vol. 24, November, pp. 404 - 411.

Garry, T. (2007), 'Consumer Sophistication and the Role of Emotion on Satisfaction Judgments within Credence Services', Journal of Consumer Behaviour . In Press.

Grönroos, C., (1984), Strategic Management and Marketing in the Service Sector, London, Chartwell-Bratt.

Hanlon, G., (1997), "A Profession in Transition? - Lawyers, The Market and Significant Others", The Modern Law Review, November, Vol. 60, No. 6, pp. 798-822.

Hart, S. and Hogg G., (1998), "Relationship Marketing in Corporate Legal Services" The Service Industries Journal, Vol. 18, No.3, pp. 55-69.

McDougall, G. \& Levesque, T. (2000), "Customer Satisfaction with Services: Putting Perceived Value into the Equation", Journal of Services Marketing, Vol. 14, No. 5, pp. 392-419.

Hennig-Thurau, T., Groth, M., Paul, M. and Gremler, D, (2006),“Are All Smiles Created Equal? How Emotional Contagion and Emotional Labor Affect Service Relationships", Journal of Marketing, Vol. 70, pp. 58-73.

Homburg, C. Koschate, N. \& Hoyer, W. (2006), "The Role of Cognition and Affect in Formation of Customer Satisfaction: A Dynamic Perspective", Journal of Marketing, Vol. 70(July), pp. 21-31. 
Jøreskog, K.G., (1993), “Testing Structural Equation Models. In: Bollen, K, and Long, J. (Eds), Testing Structural Equation Models, pp. 294-316. Newbury Park, CA: Sage.

Kumar, N., Scheer, L.K. and Steenkamp, J.E., (1998), "Interdependence, Punitive Capability and the Reciprocation of Punitive Actions in Channel Relationships", Journal of Marketing Research, Vol.35, May, pp. 225-35.

Landy, D. and Aronson, E. (1969), "The influence of the Character of the criminal and his victim on the decision of simulated jurors", Journal of Experimental Social Psychology, Vol. 5, pp.141-152.

Mano, H. and Oliver, R.L. (1993), "Assessing the Dimensionality and Structure as Consumption Experience: Evaluation, Feeling and Satisfaction", Journal of Consumer Research, Vol. 20, pp. 451-466.

Nosanchuk, T.A. , (1972), "The vignette as an experimental approach to the study of social status: An exploratory study”, Social Science Research Vol. 1, pp. 107-120.

Nyer, .U; P. (1997), "A Study of the Relationships Between Cognitive Appraisals and Consumption Emotions", Journal of the Academy of Marketing Science, Vol. 25, No. 4, pp. 296-304.

Odekerken-Schroder, G.,van Birgelen, M., Lemmink, J., de Ruyter, K., (2000) "Moments of Sorrow and Joy: An Empirical Assessment of the Complementary Value of Critical Incidents in Understanding and Customer Service Evaluations", European Journal of Marketing, Vol. 34, No.1/2, pp.107-125.

Oliver, R.L., (1993), "Cognitive, Affective and Attribute Basis of the Satisfaction Response", Journal of Consumer Research, Vol. 20, pp. 418-430.

Oliver, R., L (1997), Satisfaction: A Behavioural Perspective on the Consumer, McGraw Hill,

Peck, J. and Wiggins, J. (2006), “It Just Feels Good: Customers' Affective Response to Touch and its Influence on Persuasion", Journal of Marketing, Vol. 70 (October), pp. 56-69.

Phillips, D. \& Baumgartner, H. (2002), "The Role of Consumption Emotions in the Satisfaction Response", Journal of Consumer Psychology, Vol. 12, No. 3, pp. 243252.

Pousette, A. and Hanse, J.J, (2002), "Job Characteristics as Predictors of Ill-Health and Sickness Absenteeism in Different Occupational Types- A Multigroup Structural Equation Modelling Approach", Work and Stress, Vol. 16, No. 3, pp. 229-250.

Randall, D. and Gibson, A., (1990), "Methodology in Business Ethics Research: A Review and Critical Assessment", Journal of Business Ethics, Vol. 6, pp. 383-391 
Richins, M. (1997), "Measuring Emotions in the Consumption Experience", Journal of Consumer Research, Vol. 24, pp. 127-146.

Schoefer, K. and Ennew, C., (2005), "The Impact of Perceived Justice on Consumers' Emotional Responses to Service Complaint Experiences”, Journal of Services Marketing, Vol. 19, No. 5, pp. 261-270.

Scott-Lennox, J., and Lennox, R., (1995), "Sex-race differences in Social Support and Depression in Older Low Income Adults" , In: Hoyle, R., (Ed) Structural Equation Modeling: Concepts, Issues and Applications, pp. 76-99, London Sage.

Smith, A. and Bolton, R. (2002), "The Effect of Customers' Emotional Responses to Service Failures on their Recovery Effort Evaluation and Satisfaction Judgments", Journal of the Academy of Marketing Science, Vol. 30, No. 1, pp. 5-23.

Söderlund, M., and Rosengren, S., (2007), "Receiving Word-of-Mouth from the Service Encounter: An Emotion-based Effectiveness Assessment”, Journal of Retailing and Consumer Services, Vol. 14, pp. 123-136.

Westbrook, R.A. (1987), "Product/Consumption-Based Affective Responses and Post Purchase Processes", Journal of Marketing Research, Vol. 24, pp. 258-270.

White, C. and Yu, Y, (2005) "Satisfaction Emotions and Consumer Behavioral Intentiuons", Journal of Services Marketing, Vol. 19, No. 6, pp. 411-420.

Wood, S. and Moreau, C. (2006), "From Fear to Loathing? How Emotion Influences the Evaluation and Early Use of Innovations", Journal of Marketing, Vol. 70 (July), pp. 44-57. 


\section{Appendices}

\section{Appendix 1:}

Manipulations of the Technical, Functional and Affective Elements of the Service Encounter

\begin{tabular}{|c|c|}
\hline Technical Positive & Technical Negative \\
\hline $\begin{array}{l}\text { He explains that a distinctive trade mark will } \\
\text { distinguish the goods of one undertaking from } \\
\text { another. In other words, the application is weak as } \\
\text { it lacks the distinction required to achieve this and is } \\
\text { unlikely to be successful. He specifically cites the } \\
\text { case of Philips Electronics NV v Remington } \\
\text { Consumer Products Ltd (2002) All ER (EC) } 634 \\
\text { during his explanation. }\end{array}$ & $\begin{array}{l}\text { He specifically cites the case of Philips Electronics } \\
\text { NV v Remington Consumer Products Ltd (2002) } \\
\text { All ER (EC) } 634 \text { and explains how under similar } \\
\text { circumstances an application for trade mark } \\
\text { registration was successful. }\end{array}$ \\
\hline Functional Positive & Functional Negative \\
\hline $\begin{array}{l}\text { Sure enough, the solicitor rings you back within } 30 \\
\text { minutes and you explain the situation to him. }\end{array}$ & $\begin{array}{l}\text { However, you still have not heard back from the } \\
\text { solicitor by the following afternoon so you phone } \\
\text { again. This time you are put through and explain the } \\
\text { situation to him. }\end{array}$ \\
\hline $\begin{array}{l}\text { The correspondence arrives at your premises the } \\
\text { following day }\end{array}$ & $\begin{array}{l}\text { By the following week, the correspondence still has } \\
\text { not arrived so you phone up to chase it and are told } \\
\text { by the solicitor's secretary that she will look into it. }\end{array}$ \\
\hline Affect Positive & Affect Negative \\
\hline $\begin{array}{l}\text { The solicitor greets you warmly, listens carefully to } \\
\text { you and asks a number of questions. He tells you he } \\
\text { has a lot of experience in this area and given what } \\
\text { you have told him, the trade mark application is (un) } \\
\text { likely to succeed }\end{array}$ & $\begin{array}{l}\text { The solicitor listens to you and then curtly explains } \\
\text { that there is a good probability that the trade mark } \\
\text { would (not) be granted. }\end{array}$ \\
\hline $\begin{array}{l}\text { You continue to chat and it soon becomes apparent } \\
\text { that you know a lot of mutual acquaintances and } \\
\text { you proceed to exchange some humorous anecdotes } \\
\text { about one or two of them. The phone call concludes } \\
\text { with the solicitor assuring you that you have nothing } \\
\text { to worry about and that he will send a letter in the } \\
\text { next post summarizing his advice. }\end{array}$ & $\begin{array}{l}\text { When you attempt to ask him some questions he } \\
\text { says that from a legal perspective, that is all you } \\
\text { need to know and if you want any more information } \\
\text { than you will have to speak to his junior. There is a } \\
\text { long silence. The phone call concludes with the } \\
\text { solicitor informing you that he will send a } \\
\text { correspondence summarizing his advice together } \\
\text { with his invoice and he promptly hangs up. }\end{array}$ \\
\hline
\end{tabular}




\section{Appendix 2:}

Satisfaction Dimensions of the Cognitive and Affective Components of the Service Encounter (Based on Hart and Hogg's (1998) Service Evaluation Criteria for Legal Services and Richin's (1997) Consumption Emotions Set (CES)).

\section{Cognitive Elements}

Degree of empathy; Importance attached to legal detail; Courtesy of the partner and staff; Promptness of the advice; Degree of reassurance and confidence with which the advice was given; Accessibility of the partner; Legal knowledge of the partner ; Commerciality of the legal advice; How clearly and in language that you understood the advice was given; Reliability of the partner; Degree of attention the partner appeared to give your request; Reliability of the partner; Degree of partner involvement; Quality of the legal advice given

\section{Affective Elements}

Frustrated; Optimistic; Irritated; Calm; Amazed; Nervous; Surprised; Tense; Thrilled; Sad; Peaceful; Scared; Happy; Panicky; Encouraged; Contented; Humiliated; Joyful; Afraid; Enthusiastic; Depressed; Guilty; Relieved; Hopeful; Worried; Pleased; Angry; Excited; Miserable; Eager; Embarrassed; Fulfilled; Astonished; Discontented; Proud; Unfulfilled; Ashamed.

\section{Appendix 3:}

Exploratory Factor Analysis Results (Affective Component of the Service Encounter)

\begin{tabular}{|l|c|c|}
\hline Items & $\begin{array}{c}\text { Factor 1: } \\
\text { Negative } \\
\text { Affect }\end{array}$ & $\begin{array}{c}\text { Factor 2: } \\
\text { Positive } \\
\text { Affect }\end{array}$ \\
\hline Sad & .805 & \\
\hline Nervous & .795 & \\
\hline Scared & .791 & \\
\hline Afraid & .786 & \\
\hline Panicky & .772 & \\
\hline Tense & .756 & \\
\hline Depressed & .737 & \\
\hline Miserable & .725 & \\
\hline Humiliated & .716 & \\
\hline Angry & .698 & \\
\hline Unfulfilled & .687 & \\
\hline Embarrassed & .686 & \\
\hline Surprised & .678 & \\
\hline Worried & .656 & \\
\hline Discontented & .642 & \\
\hline Ashamed & .626 & \\
\hline Astonished & .612 & \\
\hline Enthusiastic & & .882 \\
\hline Pleased & & .857 \\
\hline Encouraged & & .831 \\
\hline Happy & & .822 \\
\hline Relieved & & .822 \\
\hline Excited & & .814 \\
\hline Content & & .804 \\
\hline Joyful & & .792 \\
\hline Hopeful & & .786 \\
\hline Optimistic & & .775 \\
\hline Fulfilled & & .736 \\
\hline Proud & & .676 \\
\hline Thrilled & & .668 \\
\hline Eager & & \\
\hline & & \\
\hline
\end{tabular}




\section{Appendix 4:}

Exploratory Factor Analysis Results (Cognitive Components of the Service Encounter)

\begin{tabular}{|l|c|c|c|}
\hline \multicolumn{1}{|c|}{ Items } & $\begin{array}{c}\text { Factor 1: } \\
\text { Interaction } \\
\text { Component }\end{array}$ & $\begin{array}{c}\text { Factor 2: } \\
\text { Technical } \\
\text { Component }\end{array}$ & $\begin{array}{c}\text { Factor 3: } \\
\text { Responsiveness } \\
\text { Component }\end{array}$ \\
\hline Degree of empathy & .867 & & \\
\hline Courtesy of partners and staff & .802 & & \\
\hline Degree of partner involvement & .726 & & \\
\hline Degree of reassurance and confidence & .694 & & \\
\hline Clear and understandable language & .637 & & \\
\hline Legal knowledge of partners & & .883 & \\
\hline Quality of the legal advice given & & .837 & \\
\hline Commerciality of legal advice & & & .720 \\
\hline Promptness of advice & & & 758 \\
\hline Accessibility of partner & & & \\
\hline
\end{tabular}

\section{Appendix 5:}

Confirmatory Factor Analysis (Factor Intercorrelations)

\begin{tabular}{|cc|}
\hline \multicolumn{1}{|c|}{ Correlation } & Estimate \\
\hline Technical Satisfaction $\longleftrightarrow$ Interaction Satisfaction & .447 \\
Interaction Satisfaction $\longrightarrow$ Responsiveness Satisfaction & .711 \\
Technical Satisfaction $\longleftrightarrow$ Responsiveness Satisfaction & .619 \\
\hline
\end{tabular}




\section{Appendix 6:}

Confirmatory Factor Analysis (Standardised Regression Weights ( $p<.001$ for all items))

\begin{tabular}{|c|c|c|}
\hline & Regression Path & Base Line Model Estimates \\
\hline Technical Component & & \\
\hline Technical Component & $\longrightarrow$ Quality & .815 \\
\hline Technical Component & $\longrightarrow$ Commerciality & .676 \\
\hline Technical Component & $\longrightarrow$ Knowledge & .803 \\
\hline Interactive Component & & \\
\hline Interactive Component & $\longrightarrow$ Involvement & .802 \\
\hline Interactive Component & $\rightarrow$ Reassurance & .771 \\
\hline Interactive Component & $\rightarrow$ Courtesy & .774 \\
\hline Interactive Component & $\longrightarrow$ Language & .570 \\
\hline Interactive Component & $\rightarrow$ Empathy & .754 \\
\hline Responsiveness & & \\
\hline Responsiveness $\longrightarrow$ & Promptness & .756 \\
\hline Responsiveness $\longrightarrow$ & Accessibility & .737 \\
\hline Responsiveness $\longrightarrow$ & Reliability & .752 \\
\hline Negative Affect $\left(R^{2}\right)$ & & .287 \\
\hline Negative Affect - & Afraid & .724 \\
\hline Negative Affect & Scared & .725 \\
\hline Negative Affect & Nervous & .758 \\
\hline Negative Affect & Sad & .798 \\
\hline Negative Affect & Tense & .737 \\
\hline Negative Affect & Depressed & .729 \\
\hline Negative Affect & Miserable & .751 \\
\hline Negative Affect & Humiliated & .712 \\
\hline Negative Affect & Angry & .716 \\
\hline Negative Affect & Unfulfilled & .705 \\
\hline Negative Affect & Embarrassed & .654 \\
\hline Negative Affect & Surprised & .641 \\
\hline Negative Affect & Worried & .633 \\
\hline Negative Affect & Discontent & .664 \\
\hline Negative Affect & Ashamed & .587 \\
\hline Negative Affect & Astonished & .603 \\
\hline Positive Affect $\left(R^{2}\right)$ & & .337 \\
\hline Positive Affect & Happy & .827 \\
\hline Positive Affect & Encouraged & .866 \\
\hline Positive Affect & Pleased & .884 \\
\hline Positive Affect & Enthusiastic & .900 \\
\hline Positive Affect & Relieved & .848 \\
\hline Positive Affect & Excited & .766 \\
\hline Positive Affect & Joyful & .762 \\
\hline Positive Affect & Hopeful & .786 \\
\hline Positive Affect & Optimistic & .750 \\
\hline Positive Affect & Fulfilled & .738 \\
\hline Positive Affect & Proud & .632 \\
\hline Positive Affect & Thrilled & .587 \\
\hline Positive Affect & Eager & .600 \\
\hline Satisfaction $\left(R^{2}\right)$ & & .687 \\
\hline
\end{tabular}




\section{Appendix 7:}

Partially Constrained Model 1 and Model 2: Parameter Estimates for LPC Respondents

\begin{tabular}{|c|c|c|}
\hline Path & Model 1 & Model 2 \\
\hline \multicolumn{3}{|l|}{ Positive Affect } \\
\hline Technical Satisfaction $\longrightarrow$ Positive Affect & $-.318 *$ & \\
\hline Positive Affect $\longrightarrow$ Technical Satisfaction & & -193 \\
\hline Interactive Satisfaction $\longrightarrow$ Positive Affect & $.364^{*}$ & $.325^{*}$ \\
\hline Responsiveness Satisfaction $\longrightarrow$ Positive Affect & .116 & -.024 \\
\hline \multicolumn{3}{|l|}{ Negative Affect } \\
\hline Technical Satisfaction $\longrightarrow$ Negative Affect & -.028 & \\
\hline Negative Affect $\longrightarrow$ Technical Satisfaction & & .212 \\
\hline Interactive Satisfaction $\longrightarrow$ Negative Affect & $.680^{*}$ & $.677^{*}$ \\
\hline Responsiveness Satisfaction $\longrightarrow$ Negative Affect & -.053 & -.066 \\
\hline \multicolumn{3}{|l|}{ Satisfaction } \\
\hline Technical Satisfaction $\longrightarrow$ Satisfaction & $.231 *$ & $.247 *$ \\
\hline Interactive Satisfaction $\longrightarrow$ Satisfaction & $.480^{*}$ & $.513 *$ \\
\hline Responsiveness Satisfaction $\longrightarrow$ Satisfaction & $.313^{*}$ & $.335^{*}$ \\
\hline Positive Affect $\longrightarrow$ Satisfaction & $.200^{*}$ & $.214^{*}$ \\
\hline Negative Affect $\longrightarrow$ Satisfaction & -.123 & -.131 \\
\hline \multicolumn{3}{|l|}{ Overall Model Fit } \\
\hline & $x^{2}=.084(\mathrm{df}=1)$ & $x^{2}=17.51(\mathrm{df}=3)$ \\
\hline & $\begin{array}{c}p=.772 \\
\mathrm{GFI}=999\end{array}$ & $\begin{array}{c}p=.001 \\
\mathrm{GFI}=.915\end{array}$ \\
\hline & AGFI $=.989$ & $\mathrm{AGFI}=.405$ \\
\hline & RMSEA $=.00$ & RMSEA $=.29$ \\
\hline & $\mathrm{NFI}=.999$ & $\mathrm{NFI}=.864$ \\
\hline & $\mathrm{CFI}=1.000$ & $\mathrm{CFI}=.873$ \\
\hline
\end{tabular}

* Significant at the $p<.05$ probability level 


\section{Appendix 8:}

Partially Constrained Model 1 and Model 2: Parameter Estimates for NLPC Respondents

\begin{tabular}{|c|c|c|}
\hline Path & Model 1 & Model 2 \\
\hline \multicolumn{3}{|l|}{ Positive Affect } \\
\hline Technical Satisfaction $\longrightarrow$ Positive Affect & $.287^{*}$ & \\
\hline Positive Affect $\longrightarrow$ Technical Satisfaction & & $.514^{*}$ \\
\hline Interactive Satisfaction $\longrightarrow$ Positive Affect & $.358^{*}$ & $.424 *$ \\
\hline Responsiveness Satisfaction $\longrightarrow$ Positive Affect & .139 & .250 \\
\hline \multicolumn{3}{|l|}{ Negative Affect } \\
\hline Technical Satisfaction $\longrightarrow$ Negative Affect & -.010 & \\
\hline Negative Affect $\longrightarrow$ Technical Satisfaction & & .111 \\
\hline Interactive Satisfaction $\longrightarrow$ Negative Affect & $.418^{*}$ & $.416^{*}$ \\
\hline Responsiveness Satisfaction $\longrightarrow$ Negative Affect & .036 & .033 \\
\hline \multicolumn{3}{|l|}{ Satisfaction } \\
\hline Technical Satisfaction $\longrightarrow$ Satisfaction & $.220^{*}$ & $.225^{*}$ \\
\hline Interactive Satisfaction $\longrightarrow$ Satisfaction & $.354 *$ & $.361^{*}$ \\
\hline Responsiveness Satisfaction $\longrightarrow$ Satisfaction & .195 & .199 \\
\hline Positive Affect $\longrightarrow$ Satisfaction & .163 & .167 \\
\hline Negative Affect $\longrightarrow$ Satisfaction & .066 & .067 \\
\hline & $x^{2}=.484(\mathrm{df}=1)$ & $x^{2}=8.22(\mathrm{df}=3)$ \\
\hline & $\begin{array}{c}p=.486 \\
G \mathrm{GF}=997\end{array}$ & $\begin{array}{c}p=.042 \\
G F I=060\end{array}$ \\
\hline & AGFI $=.945$ & AGFI $=.722$ \\
\hline & RMSEA $=.00$ & RMSEA $=.16$ \\
\hline & $\mathrm{NFI}=.997$ & $\mathrm{NFI}=.952$ \\
\hline & $\mathrm{CFI}=1.000$ & $\mathrm{CFI}=.967$ \\
\hline
\end{tabular}

* Significant at the $p<.05$ probability level 